\title{
Gene expression changes linked to antimicrobial resistance, oxidative stress, iron depletion and retained motility are observed when Burkholderia cenocepacia grows in cystic fibrosis sputum Pavel Drevinek ${ }^{1}$, Matthew TG Holden ${ }^{2}$, Zhaoping Ge ${ }^{3}$, Andrew M Jones ${ }^{4}$, Ian Ketchell ${ }^{5}$, Ryan T Gill ${ }^{6}$ and Eshwar Mahenthiralingam*1
}

Address: ${ }^{1}$ Cardiff School of Biosciences, Cardiff University, Cardiff, UK, ${ }^{2}$ The Wellcome Trust Sanger Institute, Cambridge, UK, ${ }^{3}$ Center for Bioinformatics, University of North Carolina, Chapel Hill, NC, USA, ${ }^{4}$ Bradbury Cystic Fibrosis Unit, Wythenshawe Hospital, Manchester, UK, ${ }^{5}$ Cardiff Adult Cystic Fibrosis Centre, Llandough Hospital, Penarth, UK and ${ }^{6}$ Department of Chemical and Biological Engineering, University of Colorado, Boulder, CO, USA

Email: Pavel Drevinek - pavel.drevinek@lfmotol.cuni.cz; Matthew TG Holden - mh3@sanger.ac.uk; Zhaoping Ge - gezhaoping@hotmail.com; Andrew M Jones - Andrew.Jones@smuht.nwest.nhs.uk; Ian Ketchell - Ian.Ketchell@CardiffandVale.wales.nhs.uk; Ryan T Gill -rtg@colorado.edu; Eshwar Mahenthiralingam* - MahenthiralingamE@cardiff.ac.uk

* Corresponding author

Published: 19 September 2008

BMC Infectious Diseases 2008, 8:121 doi:10.1186/147I-2334-8-121
Received: 12 June 2008

Accepted: 19 September 2008

This article is available from: http://www.biomedcentral.com/I47I-2334/8/I2I

(c) 2008 Drevinek et al; licensee BioMed Central Ltd.

This is an Open Access article distributed under the terms of the Creative Commons Attribution License (http://creativecommons.org/licenses/by/2.0), which permits unrestricted use, distribution, and reproduction in any medium, provided the original work is properly cited.

\begin{abstract}
Background: Bacteria from the Burkholderia cepacia complex (Bcc) are the only group of cystic fibrosis (CF) respiratory pathogens that may cause death by an invasive infection known as cepacia syndrome. Their large genome (> 7000 genes) and multiple pathways encoding the same putative functions make virulence factor identification difficult in these bacteria.
\end{abstract}

Methods: A novel microarray was designed to the genome of Burkholderia cenocepacia J23I5 and transcriptomics used to identify genes that were differentially regulated when the pathogen was grown in a CF sputum-based infection model. Sputum samples from CF individuals infected with the same B. cenocepacia strain as genome isolate were used, hence, other than a dilution into a minimal growth medium (used as the control condition), no further treatment of the sputum was carried out.

Results: A total of 723 coding sequences were significantly altered, with 287 upregulated and 436 downregulated; the microarray-observed expression was validated by quantitative PCR on five selected genes. B. cenocepacia genes with putative functions in antimicrobial resistance, iron uptake, protection against reactive oxygen and nitrogen species, secretion and motility were among the most altered in sputum. Novel upregulated genes included: a transmembrane ferric reductase (BCAL0270) implicated in iron metabolism, a novel protease (BCAL0849) that may play a role in host tissue destruction, an organic hydroperoxide resistance gene (BCAM2753), an oxidoreductase (BCALI I07) and a nitrite/sulfite reductase (BCAMI676) that may play roles in resistance to the host defenses. The assumptions of growth under iron-depletion and oxidative stress formulated from the microarray data were tested and confirmed by independent growth of $B$. cenocepacia under each respective environmental condition.

Conclusion: Overall, our first full transcriptomic analysis of B. cenocepacia demonstrated the pathogen alters expression of over $10 \%$ of the 7176 genes within its genome when it grows in CF sputum. Novel genetic pathways involved in responses to antimicrobial resistance, oxidative stress, and iron metabolism were revealed by the microarray analysis. Virulence factors such as the cable pilus and Cenocepacia Pathogenicity Island were unaltered in expression. However, B. cenocepacia sustained or increased expression of motility-associated genes in sputum, maintaining a potentially invasive phenotype associated with cepacia syndrome. 


\section{Background}

Cystic fibrosis (CF) is the most common hereditary disease in Caucasian population affecting one in every 2,500 - 4,500 newborns. People with CF lack a functional chloride transporter normally present in epithelial cell membranes which results in multiple organ system impairment. The respiratory tract is one of the most profoundly affected systems where the defect in ion transport causes production of highly viscous mucus. The resulting ineffective mucocilliary clearance in the lung leads to colonization of the airway with several bacterial pathogens and ultimately it is respiratory infections that are the major cause of morbidity and mortality in individuals with CF. The most problematic bacterial infections are caused by Pseudomonas aeruginosa and the Burkholderia cepacia complex (Bcc), and are characterized by low responsiveness to antibiotic therapy and significant reductions in a patient's lung function. Both bacteria also pose the risk of epidemic spread within the CF community $[1,2]$, with the Bcc being distributed among CF patients to much smaller extent (3 - 30\%; [3] compared to P. aeruginosa $70-80 \%$; [1]). However, the clinical relevance of Bcc infection is underlined by the fact that it is the only known CF pathogen which can enter the blood circulation and lead to fulminating septicaemia with acute respiratory failure called "cepacia syndrome" [2]. The Bcc represents a broad collection of closely related bacterial species, of which Burkholderia cenocepacia and Burkholderia multivorans are the most dominant species in CF infection [1].

Although rapid clinical decline and epidemic spread is linked to infection with a number of Bcc species, B. cenocepacia is regarded as one of the most virulent and problematic CF pathogens [2]. This species accounts for 50 $90 \%$ of all Bcc infections diagnosed in CF patients in different national CF centres $[1,4]$ and includes strains with a well documented history of patient-to-patient transmission, as well as strains exhibiting a high virulence potential $[5,6]$. Several epidemic B. cenocepacia strains have been described [7]. One strain type, known as ET12, was one of the first highly transmissible strains to be described and caused multiple infection outbreaks in Canada and the United Kingdom that were associated with significant mortality among CF patients [8]. As a result of its clinical significance, the ET12 B. cenocepacia strain J2315 [7] was the first Bcc pathogen selected for genome sequence determination at the Wellcome Trust Sanger Institute. The complete J2315 genome subsequently became the basis for developing the first custom microarray of a B. cenocepacia species $[9,10]$.

A number of pathogenic traits have been identified in $B$. cenocepacia including lipopolysaccharide, various adhesins, flagella, siderophores, type III secretion system, quo- rum sensing, genomic islands, haemolysins, extracellular proteases, exopolysaccharide, resistance to antibiotics and to reactive oxygen species, and the ability to form biofilms (reviewed in [2]). Despite this extensive research, the individual contribution of each virulence determinant and their potential interaction with other virulence factors during CF infection has not been extensively addressed. In addition, Burkholderia genomes are among the largest in bacteria ranging from $6 \mathrm{Mb}$ to greater $9 \mathrm{Mb}$ [11]. Their genomes also contain multiple pathways for related functions and considerable gene redundancy due to presence of paralogous genes [12]. Hence, pin-pointing which genes are active in specific environments is not straightforward due to the large number of predicted functional redundancies in their genomes.

In order to characterize the molecular processes that take place in B. cenocepacia at an early stage of infection, we studied the global gene expression changes that occur during growth in CF sputum modelled under laboratory conditions. By using a genomic microarray approach, we were also able to profile expression and uncover which of the many paralogous gene systems in B. cenocepacia are active in an environment mimicking infection. Examining gene expression in sputum-based models has only been performed with $P$. aeruginosa, using UV-irradiated CF sputum [13] or artificial sputum [14]. In this first complete study of $B$. cenocepacia sputum-transcriptomics, we were able to work with CF sputum samples in a non-sterilized, close to native form since the $\mathrm{CF}$ individuals examined were chronically infected with ET12 strains that were determined by microbial reference centres using standard procedures $[1,2]$ to be genetically identical to our experimental strain J2315. The transcriptome of a B. cenocepacia population resulting directly from the pathogenhost interaction in sputum from three CF individuals was measured using multiple biological replicates. A complex picture of the pathophysiological state of B. cenocepacia during an early stage of infection was developed by interpreting the expression levels of individual genes that were specifically activated or suppressed in the CF sputum environment. Pathogenic traits that were altered in this model of growth during respiratory infection included activation of protective mechanisms against antibiotics and reactive oxygen species, a response to balance changes in concentration of internal iron, and upregulation of two well known virulence factors, flagella and metalloproteases.

\section{Methods \\ Microarray}

A custom $2 \times 11 \mathrm{~K}$ microarray for $B$. cenocepacia was developed using Agilent's two colour 60-mer ink jet synthesis platform (Agilent Technologies, Santa Clara, California). A partial genomic microarray and labelling procedures using this technology had already been validated [10]. 
The microarray was composed of 10,807 probes which were specific to the following features; annotated J2315 CDS (a total 7,251 probes including duplicate probes for several genes), selected J2315 intergenic regions $(1,489)$, probes for CDS specific to other two sequenced B. cenocepacia strains AU1054 and HI2424 $(1,457)$, and 610 probes serving as technical controls (the array definition file is deposited in ArrayExpress under the accession number A-MEXP-867). The genome sequence of $B$. cenocepacia strain J2315 was produced by the Pathogen Sequencing Group at the Sanger Institute, Hinxton, Cambridge http://www.sanger.ac.uk/Projects/B cenocepacia, and the sequences of strains AU1054 and HI2424 were produced by the produced by the US Department of Energy Joint Genome Institute http://www.jgi.doe.gov.

\section{Sputum samples}

The respiratory samples were obtained from adult CF patients as routine diagnostic specimens sent for microbiological analysis. For each patient the clinical condition, bacterial infection and antibiotics administered have been summarised in Table 1. Sputa from three CF patients infected with the ET12 B. cenocepacia were used in the microarray based analysis: patient 1 and patient 2 were clinically stable at the time of sampling (sputum 1 and 2), while patient 3 was suffering an exacerbation (sputum 3; Table 1). Subsequently, along with sputum 2 and 3, three additional sputum samples from three further CF patients were examined using quantitative PCR to validate the microarray observed gene expression: patient 4 (sputum 4) was infected with $B$. cenocepacia and clinically stable; patient 5 (sputum 5 ) was infected only with $P$. aeruginosa and exacerbating, and patient 6 (sputum 6 ) was also only infected with $P$. aeruginosa but stable at the time the sample was provided (Table 1).

Each sputum sample was stored frozen in its native form at $-20^{\circ} \mathrm{C}$ and upon arrival to the research laboratory, they were thawed, diluted in a minimal basal salts medium (BSM) containing $14.3 \mathrm{mM}$ glucose and $0.05 \%$ casamino acids [15] to a concentration of $12.5 \% \mathrm{w} / \mathrm{vol}$, homogenized by passage through a $10 \mathrm{ml}$ syringe $20 \times$ and archived at $-20^{\circ} \mathrm{C}$. The total iron concentration of the sputum samples and basal salts media was determined using standard atomic adsorption spectrometry at $248.3 \mathrm{~nm}$ in an air acetylene flame (Varian SpectrAA-100 running Spectra-100 Version 2 Software). A standard curve was prepared using a spectrosol iron standard (VWR Scientific, UK).

\section{Growth conditions}

All incubations were carried out at $37^{\circ} \mathrm{C}$ with shaking in an orbital shaker set at $220 \mathrm{rpm}$. A $3 \mathrm{ml}$ starter culture of J2315 (harvested at mid-log growth phase growth in Luria-Bertani broth; $\left.\mathrm{OD}_{600 \mathrm{~nm}} 0.5\right)$ was split into two aliquots and centrifuged $(8$ minutes, $650 \times \mathrm{g})$. The pellet was resuspended in $3 \mathrm{ml} \mathrm{BSM}$ and $1 \mathrm{ml}\left(\sim 1 \times 10^{8}\right.$ colony forming units; cfu) inoculated into either: (i) $4 \mathrm{ml}$ BSM (control) or, (ii) $4 \mathrm{ml}$ BSM supplemented with homogenized CF sputum at $12.5 \% \mathrm{w} / \mathrm{vol}$, giving a final sputum concentraton of $10 \% \mathrm{w} / \mathrm{vol}$ in the $5 \mathrm{ml}$ culture volume (test). Incubation was continued until the culture optical density had increased by $\mathrm{OD}_{600 \mathrm{~nm}} 0.6$ (an equal increase in culture density rather than an equal time period of incubation). For each experiment this meant that growth started at an $\mathrm{OD}_{600 \mathrm{~nm}}$ of between 0.3 and 0.4 and was then harvested at an $\mathrm{OD}_{600 \mathrm{~nm}}$ of between 0.9 and 1.0, providing sufficient time for $B$. cenocepacia to adapt is gene expression to the new growth condition. After growth, the cultures were then immediately cooled in liquid nitrogen and briefly centrifuged ( 1 minute, $160 \times \mathrm{g}, 4^{\circ} \mathrm{C}$ ) to remove heavy particulate matter. To lyse human cells and enable better purification of bacteria specific RNA, the supernatants were mixed with an equal volume of $0.2 \%$ Triton X-100 in BSM, left for 10 minutes on ice, diluted with 5 volumes of BSM and centrifuged to collect the bacteria ( 5 minutes, $5,000 \times \mathrm{g}, 4^{\circ} \mathrm{C}$ ). The resulting pellets were snap frozen in liquid nitrogen and stored at $-80^{\circ} \mathrm{C}$.

\section{RNA extraction, labelling and hybridization}

Total RNA was isolated using RNeasy Mini Kit (Qiagen) according to the manufacturer's instructions including the optional step of homogenization with a QIAshredder spin columns. To increase RNA yield, we performed an additional sonication step at the beginning of RNA isolation $(10 \times 10$ second pulses, each at $5 \mu \mathrm{m}$ amplitude, with a Sanyo Soniprep 150 Watt sonicator). After the extraction, the RNA was concentrated by using 7.5 M Lithium Chloride (Ambion). Between $4.5-15 \mu \mathrm{g}$ of RNA was used to synthesize and form labelled cDNA with the CyScribe

Table I: Sputum samples examined

\begin{tabular}{llll}
\hline Patient (sputum) number: & Patient's clinical status: & Infection: & Antibiotic treatment: \\
\hline I & Clinically stable & B. cenocepacia & azithromycin, flucloxacillin, aztreonam, tobramycin \\
2 & Clinically stable & B. cenocepacia & azithromycin, minocycline \\
3 & Pulmonary exacerbation & B. cenocepacia & azithromycin, ceftazidime, gentamicin \\
4 & Clinically stable & B. cenocepacia & azithromycin, flucloxacillin \\
5 & Pulmonary exacerbation & P. aeruginosa & meropenem, tobramycin \\
6 & Clinically stable & P. aeruginosa & ciprofloxacin, tobramycin \\
\hline
\end{tabular}


Post-Labelling Kit (an indirect amino-allyl procedure) following the manufacturer's instructions (Amersham). The fluorescent signal of each labelled sample was checked by electrophoretic separation of $1 \mu \mathrm{l}$ of sample in a mini-agarose gel followed by scanning (GeneTAC GTLS IV Scanner, Genomic Solutions Inc.). Equal intensities of Cy3- and Cy5-labelled cDNA (approximately $0.5 \mu \mathrm{g}$ of each) were combined and left to hybridize to the microarray at $65^{\circ} \mathrm{C}$ for 17 hours. The microarray slides were washed according the manufacturer's instructions (Agilent's microarray processing protocol) with initial washes in the solutions containing two different concentrations of SSPE and Nlauroylsarcosine, and a final wash in the Stabilization and Drying Solution. Signal intensities were scanned with the DNA Microarray Scanner (Agilent) and processed with the Feature Extraction v8.1 software (Agilent).

\section{Microarray experimental design and analysis}

For each patient's sputum, growth and RNA extraction was performed as two independent technical replicates. Each technical replicate comprised a direct comparison of paired Cy3-labelled control (growth in BSM) and Cy5labelled test (growth in sputum) conditions. Biological replicates were generated by combining analysis of the three CF patients' samples. In addition, a self-hybridization control experiment was performed to evaluate and overcome potential gene-specific dye bias. cDNA from all the control samples, in both Cy3- and Cy5-linked forms, were combined and hybridized on two replicate microarrays. The experimental protocols and raw microarray data can be found in ArrayExpress under the accession number E-MEXP-1261.

Gene expression data analysis was performed using GeneSpring GX 7.3 (Agilent) and only features dedicated to
J2315 (i.e., 7,251 CDS and 1,489 intergenic regions) were included in the analysis. Microarray data was examined in two ways. Initially, the three patient-specific biological replicates were each tested using Student's one-sample ttest and their changes in gene expression were defined by fold change relative to the gene expression level in selfhybridization assay; this analysis was performed with a two-fold change filter applied and no multiple testing correction or statistical significance filter of $p<0.05$ adopted. The second analysis involved applying the same statistical testing to the original, unmodified combined dataset of six technical replicates in order to identify reproducible trends that result from growth of B. cenocepacia in sputum. This analysis was performed with the false discovery rate algorithm applied and a statistical filter of $\mathrm{p}<0.05$ adopted.

\section{Quantitative PCR}

In order to validate microarray results, five genes with identified altered expression in sputum (4 overexpressed: BCAL0270, BCAM2753, BCAL1107 and BCAM1676; and 1 underexpressed: BCAL1165) were examined individually by using either semi-quantitative reverse transcriptase PCR (RT-PCR) or Real Time PCR (RQ-PCR) approaches. PCR primers targeting the test genes are shown in Table 2. The gene phaC (BCAL1861), with constant expression in both control and test microarrays, was used as a control for all quantitative PCR work and amplified using previously described primers [16]; Table 2). Irrespective of growth condition, BCAL1861 possessed a raw fluorescent microarray signal lying above the 75th percentile of all genes with unaltered expression (fold change 0.6671.334; among approximately 2,500 genes). This also demonstrated that the BCAL1861 transcript was highly abundant in all growth conditions. The semi-quantitative

Table 2: PCR primers and conditions for quantitative PCR

\begin{tabular}{|c|c|c|c|}
\hline Gene & Forward and reverse primer $\left(5^{\prime}-3^{\prime}\right)$ & Product size (bp) & $\operatorname{Tm}\left({ }^{\circ} \mathrm{C}\right)$ \\
\hline \multicolumn{4}{|l|}{ Real-time PCR } \\
\hline Control gene BCALI86I (phaC) & $\begin{array}{l}\text { AGACGGCTTCAAGGTGGT } \\
\text { ACACGGTGTTGACCGTCA }\end{array}$ & 470 & $62 / 66$ \\
\hline BCAL0270 & $\begin{array}{l}\text { GCGCGAACCCGATCGAATTC } \\
\text { GCCCGCATCCACCAGAAGTG }\end{array}$ & 400 & 66 \\
\hline BCAM 2753 & $\begin{array}{l}\text { GAACCGCAGACGCTGTACTC } \\
\text { AAACGCTCGGTGTTGCGGAC }\end{array}$ & 380 & 62 \\
\hline BCALIIO7 & $\begin{array}{l}\text { GAATCGACGTATCGGCTCGT } \\
\text { ATGATGTGCTTCGGGTTCTTG }\end{array}$ & 377 & 66 \\
\hline BCAMI676 & $\begin{array}{l}\text { GACGACCTGTTCCTGCTGTG } \\
\text { CGGCTCTTCCTGATGACGTG }\end{array}$ & 534 & 62 \\
\hline \multicolumn{4}{|l|}{ Semi-quantitative PCR } \\
\hline BCALII65 & $\begin{array}{l}\text { TGACGCTCGGCACCGTTGAC } \\
\text { GCGTGGACCTGCTCGATCTC }\end{array}$ & 400 & 66 \\
\hline
\end{tabular}


method was based on the endpoint analysis of ordinary PCR reactions varying in their number of cycles as described elsewhere [9].

More accurate levels of gene expression fold change were obtained from the RQ-PCR analysis where delta delta $\mathrm{C}_{\mathrm{T}}$ or Pfaffl methods [17] were applied. The primers and gene-specific annealing temperature for PCR conditions are provided in Table 2; each PCR reaction for semi-quantitative RT-PCR contained $0.2 \mathrm{mM}$ (each) dNTPs, $2 \mathrm{mM}$ $\mathrm{MgCl}_{2}, 0.5 \mu \mathrm{M}$ (each) primer and $0.75 \mathrm{U}$ of GoTaq polymerase (Promega, Madison, USA), while ABsolute SYBR Green Mix (Abgene, Epsom, United Kingdom) with $\mathrm{MgCl}_{2}$ concentration of $3 \mathrm{mM}$ was used for the RQ-PCR. The amplifications were run on a MJ Research PTC-200 thermal cycler with the option of real-time fluorescence detection (DNA Engine Opticon). The thermal cycling profile consisted of $15 \mathrm{sec}$ at $95^{\circ} \mathrm{C}, 30 \mathrm{sec}$ at annealing temperature (dependent on the gene being analyzed, see Table 2) and $15 \mathrm{sec}$ at $72^{\circ} \mathrm{C}$. Furthermore, the RQ-PCR profile included an initial 15 -minute incubation at $95^{\circ} \mathrm{C}$ required for hot start PCR and a melting curve analysis at the end of PCR.

A template for semi-quantitative PCR was prepared by pooling the same RNAs (representing either growth in sputum or growth in BSM) used previously for microarrays. In addition, we generated five more RNAs from additional growth experiments with five other sputum samples (carried out in accordance with the protocol for growth of J2315 in sputum) and four other RNAs which had represented a response of $\mathrm{J} 2315$ to following conditions: (i) low iron concentration (no $\mathrm{FeSO}_{4}$ in $\mathrm{BSM}$ growth medium), (ii) presence of $0.1 \% \mathrm{H}_{2} \mathrm{O}_{2}$ in $\mathrm{BSM}$; (iii) presence of $0.15 \% \mathrm{H}_{2} \mathrm{O}_{2}$; and (iv) presence of t-butyl hydroperoxide $(0.002 \%$ in BSM). Extracted RNA was converted in the amount of $0.1 \mu \mathrm{g}$ into cDNA by using Improm-II Reverse Transcription System (Promega) and $500 \mathrm{ng}$ of cDNA was added into each PCR reaction. To calculate fold change in expression when RQ-PCR method was used, every run comprised cDNAs from test (growth in sputum or other test condition) as well as from control (growth in BSM) where their gene of interest and their reference housekeeping gene phaC [16] were examined each in triplicate. The efficiency of PCR for both genes was determined by serial dilutions of control cDNA over the range of two orders of magnitude.

\section{Results \\ Extraction of B. cenocepacia RNA from sputum and microarray performance}

Initial attempts to extract RNA from bacteria grown in sputum were inconsistent due to components of sputum interfering with the procedure. Therefore a washing procedure was developed which diluted the sputum in a Triton
X100 containing buffer (to lyse human cells), gently centrifuged it to remove large particles, and finally forcefully centrifuged to collect bacteria (see Methods and Materials). Once the RNA extraction procedure had been optimised, the transcriptomic profiles of $B$. cenocepacia obtained were excellent. The array-to-array correlation within a technical duplicate from a single patient's sputum pair ranged from 0.965 to 0.985 ; variation across all 3 patients ranged from 0.894 to 0.956 . These high-correlation coefficients indicated that the custom microarrays provided good quality technical performance over the entire microarray experiment. More importantly, the > $89 \%$ similarity between biological replicates demonstrated that there was a high degree of relatedness between sputum samples resulting in a rigorous biological dataset that could be mined for gene expression changes. More than $97 \%(8,533)$ of J2315-specific features presented on the microarray were eligible for gene expression analysis as they were consistently above the background noise defined by the scanner detection calls.

\section{Microarray data analysis}

Microarray data was examined in two ways as described in Materials and Methods. The analysis based on the three biological replicates demonstrated that 182 genetic features were significantly over-expressed while 296 were down-regulated with the two fold filter applied. The alternative analysis of the entire dataset where the six arrays were handled as six independent entities revealed 950 genetic features to be significantly altered in expression, with 411 up-regulated and 539 down-regulated. A total of 454 genes overlapped both analytical approaches and only 24 genes ( 1 up- and 23 downregulated) from the three biological replicate-based analysis were not present in the larger dataset from six technical replicates. Since both analyses demonstrated excellent concordance the results were combined, adding the 24 genes from the biological replicate analysis to the 950 genetic features from the six replicates, allowing 974 genetic elements (coding sequences [CDSs], rRNA, tRNA and intergenic regions) with 2 fold or greater alteration in expression to be evaluated (see Additional Files 1 and 2 for complete lists of upand downregulated genes respectively). The low, 2-fold, threshold for a change in gene expression was selected to minimize the risk of missing false negative results. For example, multidrug efflux pump protein genes may demonstrate expression changes as low as 1.3 fold, yet such a minor change is known to dramatically alter the physiological activity of the pump [18].

Based on the parameters defined above, B. cenocepacia growth in sputum compared to growth in minimal salts medium altered the expression of 723 CDSs representing $10 \%$ of all CDSs annotated to date in the genome of J2315 (a total of 7,176). Of these CDSs, 287 were upregulated 
(see Additional File 1) and 436 downregulated (see Additional File 2). In addition, 33 tRNAs, 2 rRNAs and 2 small RNAs were found over-expressed (Additional File 1). The upregulation of tRNAs may have resulted as a direct consequence of $B$. cenocepacia growth in sputum-enriched BSM which effectively made it a nutrient-rich medium.

Interestingly, approximately one quarter (24.2\%) of the differentially expressed genes were unique to strain J2315 in comparison to the complete genomes of other B. cenocepacia strains (AU1054 and HI2424); specifically 29\% of the upregulated CDSs and $21 \%$ of the downregulated CDSs were unique to J2315. Also, around $10 \%$ of these unique CDSs were found in indel regions rather than in genomic islands region (11.8\% of upregulated and $8.0 \%$ of downregulated). Although 18\% (130/723) of the CDSs with altered expression lacked functional descriptions, the remaining CDSs differentially expressed in the presence of sputum were composed of several functional groups. Major classes of B. cenocepacia genes with altered expression in sputum were selected from the microarray dataset for further discussion and analysis, including genes playing a role in virulence, antimicrobial resistance, iron uptake, protection against reactive oxygen species (ROS) and nitrogen species, bacterial attachment, motility and secretion.

\section{Validation of microarray expression data}

We confirmed the microarray data by both semi-quantitative reverse transcriptase PCR and Real-Time PCR (RQPCR) designed to target five genes with altered expression and one control gene of constant expression (Table 2 and 3 ). The target genes selected were representative of: (i) a range of observed changes in expression (from 6- to 66fold), and (ii) different functional classes of genes with altered expression (Table 3). Semi-quantitative PCR was initially applied to BCAL0270, encoding a putative ferric reductase transmembrane protein ( $36 \times$ upregulated), and BCAL1165, a conserved hypothetical gene $(6 \times$ downregulated; RQ-PCR analysis of this gene was not possible due to limited sensitivity). Using pooled cDNA from the microarray experiments, in the sputum growth condition BCAL0270 was consistently amplified after 5 fewer cycles in comparison to the phaC (BCAL1861) house-keeping control gene while in contrast, BCAL1165 was not amplified until 35 cycles in comparison to the control gene BCAL1861 (Figure 1); this corroborated the microarray data showing that BCAL0270 was upregulated and BCAL1165 downregulated in sputum. During growth in BSM signals for BCAL270, BCAL1165 and the control phaC gene all appeared after 30 cycles (Figure 1) indicating similar levels of relative expression for all these genes in this growth condition. Although a signal for the control gene was absent in sputum yet present in BSM at 30 cycles of amplification (Figure 1), this probably resulted from

Table 3: Confirmation of B. cenocepacia gene expression by Real Time PCR

\begin{tabular}{|c|c|c|c|c|}
\hline \multirow[b]{2}{*}{$\begin{array}{l}\text { Gene expression determined from } \\
\text { (infection; clinical condition): }\end{array}$} & \multicolumn{4}{|c|}{ Real-time PCR fold change using delta delta $C_{T}$ method } \\
\hline & $\begin{array}{c}\text { BCAL0270 } \\
\text { (ferric reductase } \\
\text { transmembrane component) }\end{array}$ & $\begin{array}{c}\text { BCAM2753 } \\
\text { (ohr gene, organic } \\
\text { hydroperoxide resistance protein) }\end{array}$ & $\begin{array}{c}\text { BCALI I } 07 \\
\text { (oxidoreductase) }\end{array}$ & $\begin{array}{c}\text { BCAM I } 676 \\
\text { (nitrite/sulfite } \\
\text { reductase) }\end{array}$ \\
\hline $\begin{array}{l}\text { Microarray dataset } \\
\text { (Sputum I, 2, and 3; see below) }\end{array}$ & $\uparrow 36$ & $\uparrow 8$ & $\uparrow 66$ & $\uparrow 20$ \\
\hline $\begin{array}{l}\text { Sputum } 2 \\
\text { (B. cenocepacia; stable) }\end{array}$ & $\uparrow 160$ & $\uparrow 100$ & $\uparrow 914$ & $\uparrow 97$ \\
\hline $\begin{array}{l}\text { Sputum } 3 \\
\text { (B. cenocepacia; exacerbation) }\end{array}$ & $\uparrow 65$ & $\uparrow 40$ & $\uparrow 299$ & $\uparrow 4$ \\
\hline $\begin{array}{l}\text { Sputum } 4 \\
\text { (B. cenocepacia; stable) }\end{array}$ & $\uparrow 25$ & $\uparrow 22$ & $\uparrow 235$ & - \\
\hline $\begin{array}{l}\text { Sputum } 5 \\
\text { (P. aeruginosa; exacerbation) }\end{array}$ & $\uparrow 22$ & $\uparrow 71$ & $\uparrow 189$ & - \\
\hline $\begin{array}{l}\text { Sputum } 6 \\
\text { (P. aeruginosa; stable) }\end{array}$ & $\uparrow 3$ & $\uparrow 3$ & $\uparrow 12$ & $\uparrow 94$ \\
\hline Average for sputum growth & $\uparrow \mathbf{5 5}$ & $\uparrow 47$ & $\uparrow \mathbf{3 3 0}$ & $\uparrow 65$ \\
\hline \multicolumn{5}{|l|}{ Fold change in minimal media with: } \\
\hline $\mathrm{No} \mathrm{FeSO}_{4}$ & $\uparrow 2$ & - & & \\
\hline $0.1 \% \mathrm{H}_{2} \mathrm{O}_{2}$ & - & $\uparrow 5$ & & \\
\hline $0.15 \% \mathrm{H}_{2} \mathrm{O}_{2}$ & - & $\uparrow 3$ & & \\
\hline $0.002 \%$ t-butyl hydroperoxide & - & $\uparrow 2$ & & \\
\hline
\end{tabular}


(A) Growth in sputum

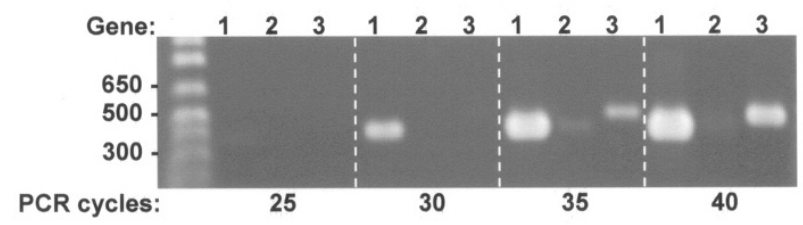

(B) Growth in minimal media

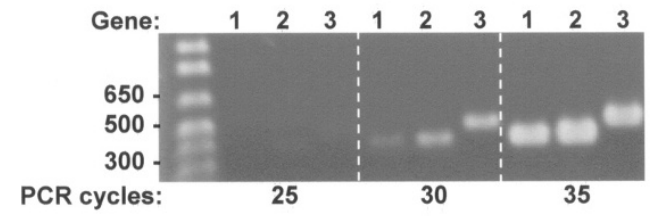

\section{Figure I}

Validation of microarray observed $B$. cenocepacia gene expression by semi-quantitative PCR. The results of semi-quantitative RT-PCR on cDNA derived from sputum-grown $B$. cenocepacia (panel $A$ ) and from cells grown under control conditions (panel $B$ ) are shown. The products amplified after set numbers of PCR cycles (labelled below each panel) are shown for the following genes: I, ferric reductase transmembrane gene (BCAL0270; up-regulated in sputum); 2, conserved hypothetical gene (BCALI I65; downregulated in sputum); and 3, phaC (BCALI86I; control gene without altered expression). Molecular size markers are shown on the left hand side of each gel and the relevant size fragments indicated in bp.

less cDNA template being present in the sputum-recovered samples, as the microarray-observed gene expression had shown that the phaC control gene was stable in expression relative to all other genes for both sputum and BSM growth.

In addition to examining the cDNA used in the microarray analysis, RQ-PCR was then applied to fresh RNA extracted from $B$. cenocepacia J2315 grown in additional aliquots of sputum samples 2 and 3 that had been used for the microarray analysis, as well as samples from three additional CF patients (Table 3). This set of RNAs allowed gene expression to be tested in multiple population replicates, accounted for biological variability between samples, and enabled the calculation of mean values of gene alteration that were more representative of CF infection conditions. Expression analysis by RQ-PCR of four selected upregulated genes correlated well with the results observed by microarray analysis (Table 3).

Quantitative PCR demonstrated that each gene was consistently upregulated after $B$. cenocepacia growth in all five different sputum samples (Table 3 ). However, the fold change of expression varied considerably, with the most extreme case being the putative oxidoreductase encoding gene (BCAL1107) whose mean fold change across the five sputum samples was 5 times greater than had been observed for the three sputum samples examined using the microarrays (Table 3). Although the differences in upregulation were substantial, all were similar to or above that seen in the microarray analysis except for expression of BCAL0270, BCAM2753, and BCAL1107 observed after $B$. cenocepacia growth in sputum 6 (Table 3 ). Each of the latter genes were still upregulated in sputum 6 compared to the control, however, the values were $12,2.5$ and 5.5 less, respectively, than those measured from the microarray dataset.

The excellent correlation between the microarray data and RQ-PCR demonstrated that the B. cenocepacia custom microarray was performing very well and also illustrated the importance of using of the three biological replicates (3 CF individuals) to provide an unbiased set of sputumgrowth microarray data. RQ-PCR data related to two selected genes (BCAL0270 and BCAM2753) will be discussed further in the relevant sections describing the functional classes of genes with altered expression during $B$. cenocepacia growth in sputum.

\section{B. cenocepacia antimicrobial resistance}

CF patients are typically treated with a combination of antibiotics including beta-lactams, macrolides, tetracyclines, aminoglycosides and polymyxins. At the time of sputum collection each patient was receiving antibiotics as follows: patient 1 was on long-term flucloxacillin and azithromycin and had just started a course aztreonam and tobramycin at the time the specimen was provided; patient 2 was receiving a course of azithromycin and minocycline, while patient 3 was on long-term azithromycin therapy with the additional prescription of ceftazidime, fluconazole and gentamicin. Hence the identification of antibiotic resistance genes with altered expression was expected due to traces of antibiotics being present in the sputum samples as a result of daily therapy.

Antibiotic efflux is known to be a primary resistance mechanism in Bcc bacteria [2]. After growth of B. cenocepacia in sputum, we detected gene expression changes in three of the multiple resistance-nodulation-cell division (RND) efflux operons [19]: BCAL1675 and BCAM1947 were upregulated while BCAL1813 was downregulated (Table 4). The ceo operon is arguably the most well characterised RND pump encoding cluster in B. cenocepacia (corresponding to genes BCAM2549-2552, 2554) [20]. We did not detect any expression changes in genes from the ceo cluster, correlating to a lack of chloramphenicol, trimethoprim or ciprofloxacin therapy in the patients examined. Significantly altered expression was also found in five more efflux transporter systems which did not 
belong to RND family (upregulated pumps were: BCAM0200, BCAM0791/792; downregulated pumps were BCAL1510, BCAL3511/514 and BCAS0015; Table $4)$.

Enzymatic inactivation is another mechanism of antibiotic resistance that is intrinsic to B. cenocepacia especially with regard to chromosomally encoded betalactamases [2]. However, none of the 4 annotated betalactamases (BCAM0393, BCAM1179, BCAM2165 and BCAS0156) in the genome were altered in expression, however, a 20-fold change in BCAS0034 was observed. This chromosome 3 encoded gene possesses a conserved metallo-betalactamase domain but whether the encoded protein may act as functional betalactamase remains to be determined. The potential effects of beta-lactam compounds being present in the sputum examined was also indicated by expression changes observed in genes encoding penicillin binding proteins, of which BCAL0704 and BCAL2832 were downregulated, while BCAM1362 was upregulated (Table 4).

\section{Iron uptake and metabolism}

Iron is an essential element required by microorganisms for many biological processes, yet its supply in a form of free, non-bound iron, is limited in the host environment. Pathogenic bacteria have evolved various iron acquisition mechanisms for the utilization of extracellular iron sources, with siderophore secretion and uptake being one of the most effective systems. B. cenocepacia produces several types of siderophore including ornibactin, pyochelin and salicylate, although the salicylate might function as a pyochelin precursor rather than a siderophore per se [21]. During the growth in sputum B. cenocepacia activated two genes involved in biosynthesis of salicylate/pyochelin ( $p c h R$; BCAM2231 and pchD; BCAM2232) and suppressed the expression of a transcriptional repressor Fur, the global iron regulator (BCAL2812). Interestingly, the gene cluster encoding biosynthesis of another $B$. cenocepacia siderophore, ornibactin (BCAL1688-1702), was not activated during sputum growth; this siderophore has, however, been shown to be important for the pathogenesis in rat model of chronic lung infection [22]. The increased demand of the bacterium for iron was also reflected by immense over-expression (> 35x) of a membrane ferric reductase (BCAL0270) which catalyzes reduction of siderophore-bound ferric ions to soluble ferrous ions.

The Tol system in P. aeruginosa is also known to mediate transport of iron-containing siderophores into bacterial cells and under iron-restricted conditions at the late log stage of growth, the $P$. aeruginosa tol genes are known to be downregulated [23]. Three B. cenocepacia genes homologous to the tol system (BCAL3201, BCAL3203-3204) were found to be downregulated in sputum suggesting that the growth environment was iron-restricted. Once in cyto- plasm, iron can be sequestered in storage proteins such as bacterioferritin or iron-sulphur proteins. We detected significantly higher expression of cyaY gene (BCAL0273, 8 fold upregulation; Table 4) which is a bacterial ortholog of a protein frataxin, an iron donor for assembly of Fe-S clusters in eukaryotes [24].

Although the infected CF lung has traditionally been considered an iron-deficient environment, this dogma has been the subject of considerable research and debate [25]. The significant expression changes in $B$. cenocepacia genes involved in the iron cycle implied that the sputum-based growth model we examined represented an iron-depleted condition. The overall iron concentration in CF sputum, approximately $3 \times 10^{-5} \mathrm{M}[26]$ is high from a bacterial growth standpoint. The total iron concentration in our $10 \%$ mixtures of sputum 2 and 3, was $3.6 \times 10^{-5} \mathrm{M}(1.98$ $\mathrm{ppm})$ and $3.5 \times 10^{-5} \mathrm{M}(1.96 \mathrm{ppm})$, respectively, and was comparable to the control basal salts medium at $3.7 \times 10^{-}$ ${ }^{5} \mathrm{M}(2.1 \mathrm{ppm})$. However, the total iron measured in sputum is composed of both ionic forms, of which only the soluble ferrous ions can be readily utilized by bacteria without using siderophores. Hence, in our experimental model the ferrous form of iron was likely to have been lower in the $10 \%$ sputum medium, than in the control BSM which contained solely soluble ferrous ions. The microarray data and RQ-PCR results on additional sputum samples had shown substantial up-regulation of a ferric reductase membrane protein gene (BCAL0270), ranging from 3 to 160 fold increases (Table 3 ), suggesting that $B$. cenocepacia gene expression was being altered due to iron limitation. To mimic the assumed iron-depleted condition and evaluate its linkage to the iron-regulated gene expression, B. cenocepacia J2315 was grown in minimal media BSM with no iron salts added $\left(4.1 \times 10^{-6} \mathrm{M}\right.$ available iron; $0.2 \mathrm{ppm}$ ) and the expression of BCAL0270 quantitated as an iron marker gene. Growth of B. cenocepacia in the low iron media resulted in a 2 fold up-regulation of BCAL0270, corroborating the assumption that its expression in sputum was being activated by a reduction in iron concentration (Table 3 ).

\section{Protection against reactive oxygen and nitrogen species}

Bacteria possess multiple mechanisms to protect themselves from toxic reactive oxygen species such as hydrogen peroxide, hydroxyl radicals, superoxide and organic hydroperoxides. Bacterial respiration and metabolism is an additional endogenous source of ROS and during growth in sputum this metabolic reservoir appeared to have increased leading to extreme up-regulation in two oxidoreductases (BCAL0269, 20-fold; BCAL1107, 65fold; Additional File 1) and cytochrome b (BCAL1106; > 90 fold; Additional File 1). Since CF patients experience chronic lung inflammation their sputum is also reservoir of harmful ROS compounds. Although we expected that a 
Table 4: Major groups of B. cenocepacia genes with altered gene expression in sputum

\begin{tabular}{|c|c|c|}
\hline Gene number: & Fold change in expression & Putative gene function: \\
\hline \multicolumn{3}{|c|}{ Antimicrobial resistance } \\
\hline \multicolumn{3}{|l|}{ upregulated } \\
\hline BCALI675 & 2.67 & multidrug efflux system transporter protein $A m r B$ \\
\hline BCAM0200 & 2.20 & efflux system transport protein \\
\hline BCAM079I & 2.11 & Major Facilitator Superfamily protein \\
\hline BCAM0792 & 2.45 & efflux system transport protein \\
\hline BCAMI362 & 2.06 & putative penicillin-binding protein \\
\hline BCAMI947 & 3.76 & putative quinoxaline efflux system transport protein \\
\hline BCAS0034 & 19.84 & metallo-beta-lactamase superfamily protein \\
\hline \multicolumn{3}{|l|}{ downregulated } \\
\hline BCAL0704 & 2.61 & D-alanyl-D-alanine carboxypeptidase (penicillin-binding protein precursor) \\
\hline BCALI5IO & 2.72 & putative multidrug resistance transporter protein \\
\hline BCALI8I3 & 2.37 & multidrug efflux system outer membrane protein \\
\hline BCAL2832 & 2.07 & D-alanyl-D-alanine carboxypeptidase/endopeptidase (penicillin-binding protein precursor) \\
\hline BCAL35II & 2.08 & multidrug resistance transporter protein \\
\hline BCAL35I4 & 2.11 & outer membrane efflux protein \\
\hline BCASO0I5 & 2.09 & efflux system transport protein \\
\hline
\end{tabular}

Iron uptake $\&$ metabolism

\begin{tabular}{lll}
\hline upregulated & & \\
BCAL0270 & 35.59 & ferric reductase-like transmembrane component \\
BCAL0273 & 8.23 & protein CyaY \\
BCAM223I & 2.86 & transcriptional regulator PchR \\
BCAM2232 & 2.11 & putative pyochelin biosynthetic protein PchD
\end{tabular}

downregulated

$\begin{array}{lll}\text { BCAL28I2 } & 2.59 & \text { putative Fur family transcriptional regulator }\end{array}$

BCAL3201 259

BCAL3203 2.18

BCAL3204 2.67

putative TolR-related protein

putative periplasmic TolB protein

putative OmpA family lipoprotein

Protection against reactive oxygen and nitrogen species

$\begin{array}{lll}\text { upregulated } & & \\ \text { BCALI766 } & 2.23 & \text { OsmC-like protein } \\ \text { BCAMI676 } & 19.99 & \text { putative nitrite/sulfite reductase } \\ \text { BCAMI677 } & 26.75 & \text { conserved hypothetical protein } \\ \text { BCAM2753 } & 8.00 & \text { putative organic hydroperoxide resistance protein, ohr gene }\end{array}$

Downregulated (none)

Motility and adherence

\begin{tabular}{lll}
\hline upregulated & & \\
BCALOI 24 & 2.02 & flagellar regulon master regulator subunit FlhD \\
BCAL0525 & 2.17 & flagellar M-ring protein FliF \\
BCAL0527 & 2.34 & flagellar protein FliS \\
BCAL3506 & 2.58 & flagellar motor switch protein FliM \\
BCAM0987 & 2.69 & flagellar hook protein 2 FlgE2 \\
BCAM2I43 & 2.33 & cable pilus associated adhesin protein \\
BCAS0299 & 3.55 & flp type pilus subunit
\end{tabular}

downregulated

BCAL3504 3.3I

BCAM2758 2.35

BCAM2759 $\quad 3.73$

BCAM276I 2.53

BCAM2762 2.81 flagellar protein FliO

two-component regulatory system, sensor kinase protein

putative minor pilin and initiator

giant cable pilus

giant cable pilus chaperone protein 
Table 4: Major groups of B. cenocepacia genes with altered gene expression in sputum (Continued)

\begin{tabular}{|c|c|c|}
\hline BCAS030I & 2.03 & putative flp type pilus leader peptidase \\
\hline \multicolumn{3}{|l|}{ Secretion } \\
\hline \multicolumn{3}{|c|}{ upregulated } \\
\hline BCAL0849 & 3.39 & metallo peptidase, subfamily M48B \\
\hline BCAL35I7 & 2.36 & type II secretion system protein $\mathrm{L}$ \\
\hline BCAM2040 & 2.98 & type III secretion system protein \\
\hline BCAM2042 & 2.16 & type III secretion system protein \\
\hline BCASOI96 & 3.25 & putative polygalacturonase \\
\hline BCAS0409 & 6.36 & zinc metalloprotease ZmpA \\
\hline \multicolumn{3}{|c|}{ downregulated } \\
\hline BCAL35I5 & 2.62 & type II secretion system protein $\mathrm{N}$ \\
\hline BCAL352I & 3.19 & type II secretion system protein I \\
\hline BCAL3522 & 2.21 & type II secretion system protein $\mathrm{H}$ \\
\hline BCAM0240 & 2.47 & $\mathrm{~N}$-acylhomoserine lactone dependent regulatory protein \\
\hline
\end{tabular}

\section{Selected gene clusters}

\begin{tabular}{|c|c|c|}
\hline \multicolumn{3}{|c|}{ upregulated } \\
\hline BCAL0269 & 20.82 & putative oxidoreductase \\
\hline BCAL0270 & 35.59 & ferric reductase-like transmembrane component \\
\hline BCALIIO6 & 90.32 & cytochrome b56I family protein \\
\hline BCALIIO7 & 65.79 & putative oxidoreductase \\
\hline BCALII53 & 3.30 & putative salicylaldehyde/benzaldehyde dehydrogenase \\
\hline BCALII56 & 2.02 & putative 4-hydroxybenzoate transporter \\
\hline BCALII57 & 2.51 & putative monooxygenase \\
\hline BCAMI676 & 19.99 & putative nitrite/sulfite reductase \\
\hline BCAMI 677 & 26.75 & conserved hypothetical protein \\
\hline BCAM 2749 & 31.39 & carboxymuconolactone decarboxylase family protein \\
\hline BCAM 2750 & 14.06 & putative exported protein \\
\hline BCAM275I & 7.13 & LysR family regulatory protein \\
\hline BCAM 2752 & 12.35 & NAD dependent epimerase/dehydratase family protein \\
\hline BCAM 2753 & 8.00 & putative organic hydroperoxide resistance protein \\
\hline BCAM2754 & 10.46 & putative ketoreductase \\
\hline \multicolumn{3}{|c|}{ downregulated } \\
\hline BCALII 30 & 2.10 & conserved hypothetical protein \\
\hline BCALII6I & 2.46 & conserved hypothetical protein \\
\hline$B C A L I \mid 62$ & 2.30 & TetR family regulatory protein \\
\hline BCALII 65 & 5.59 & conserved hypothetical protein \\
\hline BCALII 66 & 4.07 & conserved hypothetical protein \\
\hline BCALII 68 & 3.06 & conserved hypothetical protein \\
\hline BCALII69 & 2.05 & conserved hypothetical protein (pseudogene) \\
\hline BCAL3। 04 & 8.00 & urease gamma subunit \\
\hline BCAL3। 05 & 2.22 & urease beta subunit \\
\hline BCAL3I06 & 2.34 & urease alpha subunit \\
\hline BCAL3109 & 2.42 & urease accessory protein \\
\hline BCAM0066 & 5.13 & putative lipoprotein \\
\hline BCAM0067 & 14.47 & putative short chain dehydrogenase \\
\hline BCAM0068 & 11.74 & Major Facilitator Superfamily protein \\
\hline BCAM0069 & 21.83 & conserved hypothetical protein \\
\hline BCAM0070 & 15.46 & putative hydrolase \\
\hline BCAM007I & 11.11 & puatative mandelate racemase lactonizing enzyme \\
\hline BCAM0072 & 16.58 & putative thiamine pyrophosphate enzyme \\
\hline BCAM0073 & 6.85 & hypothetical protein \\
\hline BCAM0074 & 9.43 & conserved hypothetical protein \\
\hline
\end{tabular}


large number of ROS defence mechanisms to be activated, only two genes, both previously uncharaterized in B. cenocepacia, were significantly upregulated during growth in sputum. An 8-fold increase in expression of the hydroperoxide resistance gene, ohr (BCAM2753; Table 4) was observed; this gene is known to be inducible by organic peroxides [27] and to lesser extent by hydrogen peroxide [28]. The second, slightly upregulated (2.2-fold) gene was osmC (BCAL1766) that is also involved in defence against oxidative stress [29].

The significant fold change in ohr expression suggested that the induction of bacterial defence against ROS had taken place, despite the fact that antioxidant encoding genes [30] such as catalases (KatA and KatB), alkyl hydroperoxide reductases (AhpC) and superoxide dismutases (SodB and SodC), remained unaffected. To validate the oxidative stress model formulated from the microarray results, we performed further set of growth experiments where $B$. cenocepacia $\mathrm{J} 2315$ cells were exposed to sub-inhibitory levels of ROS $\left(0.1 \% \mathrm{H}_{2} \mathrm{O}_{2}, 0.15 \% \mathrm{H}_{2} \mathrm{O}_{2}\right.$ and $0.002 \%$ tert-butyl hydroperoxide, a member of organic hydroperoxides family). After RNA extraction, the expression of ohr was then determined by RQ-PCR analysis. The quantitative PCR results showed activation of ohr in all test conditions, with the greatest response occurring after exposure to $\mathrm{H}_{2} \mathrm{O}_{2}$ (Table 3), confirming the involvement of ohr in mediating $B$. cenocepacia response to both inorganic and organic forms of peroxides.

In addition to oxidative stress, infecting bacteria are threatened by nitrosative stress coming from reactive nitrogen species (RNS) such as nitric oxide radicals [31]. Although the mechanisms of enzymatic detoxification of RNS are not as well characterized as the responses to ROS, there is evidence that nitrite reductase enzyme may play an important role [32]. Growth of B. cenocepacia in sputum triggered very high expression of a nitrite/sulfite reductase (BCAM1676; 20-fold) and its neighbouring gene of unknown function (BCAM1677; 26-fold); a potential role in infection for these two genes has not been previously implicated. Also since $B$. cepacia complex bacteria are well known to be very resistant to the neutrophil-mediated non-oxidative killing [33], the significant upregulation of this nitrite/sulfite reductase pathway may form the basis for their resistant phenotype.

\section{Motility and adherence}

B. cenocepacia are motile bacteria and possess one or more flagella. In addition to mediating motility, the flagellum may also act as an adhesin establishing a primary contact with epithelial cells and playing a central role in establishing the initial phases of host colonization [2]. B. cenocepacia flagellum-mediated motility has also been shown to enable it to invade host cells [34]. Over 40 genes, which are distributed in several discrete clusters across the genome and whose expression is arranged hierarchically, contribute to the synthesis and assembly of the whole flagellum.

Growth in sputum increased the expression of flagellar structural genes (basal body MS-ring gene fliF; BCAL0525, main flagellin chaperone gene fliS; BCAL0527, C-ring gene fliM; BCAL3506, hook-protein gene flgE; BCAM0987; Table 4) as well as of one regulatory gene (flhD; BCAL0124; Table 4). In two of the three patients sputa examined, the major structural component, flagellin (fliC; BCAL0114), was also found to be overexpressed (with a 3-fold change in expression), however, the gene was excluded from the final gene list because of the filtering criteria that was applied across the entire dataset (see Methods and Materials). Only one gene associated with assembly of the flagellum was downregulated, fliO (BCAL3504; Table 4); this gene is thought to be part of the type III secretion system involved in the flagellar protein export [35]. Why this particular gene exhibited lower expression was not clear since other components of the secretion system (i.e., fliH; BCAL0523, fliI; BCAL0522, fliP; BCAL3503, fliQ; BCAL3502 and fliR; BCAL3501) did not change their level of expression and the whole system is believed to be necessary for transmembrane transport of the synthesized flagellar components.

The changes in expression of adhesins were not limited to flagellum, but also occurred in pili encoding genes. The gene for structural units of recently described type IV pili (flp; BCAS0299) [36] was found to be significantly upregulated (Table 4), although its leader peptidase exhibited slightly decreased expression (BCAS0301; Table 4). Other fimbriae affected by growth in sputum were the cable pili which are exclusively expressed by strains of ET12 clonal complex [37]. Nearly the entire cable pilus gene cluster was significantly downregulated (cblS, BCAM2758; $c b l D$, BCAM 2759; cblA, BCAM2761 and cblB, BCAM2762; Table 4) suggesting that during growth in CF sputum these surface structures are not essential. In contrast, the cable pilus adherence-mediating $22 \mathrm{kDa}$ adhesion protein (adhA; BCAM2143) [38], was found to be upregulated (Table 4).

\section{Secretion}

Bacteria use various secretory pathways to translocate exoproducts and proteins that form their external cellular structures through the membranes. Two of them, type II and type III secretion systems, exhibited altered expression in their component genes during the growth of $B$. cenocepacia in sputum. The majority of type II secretion genes were downregulated (BCAL3515, BCAL3521-3522; Table 4) with the only exception was being upregulation of BCAL3517 (Table 4). Two components of the B. cenocepacia type III secretion system showed increased expres- 
sion (BCAM2040 and BCAM2042; Table 4). Type II secretion systems have an evolutionary relationship with the Type IV pilus [39], a component of which, BCAS0299, was also upregulated (Table 4); Type III secretion systems share homology with the flagella gene systems [40] which were also upregulated in $B$. cenocepacia. The upregulation of all the latter systems suggest that there may be a common regulatory mechanism present that controls their transcription in B. cenocepacia.

Many bacterial exoproducts are known to play important roles in infection and two proteases with altered gene expression were notable in the context of $B$. cenocepacia virulence in CF. The ZmpA metalloprotease is a well characterised Bcc virulence factor which is known to play a role during infection when examined rat chronic lung infection model [41]. The gene encoding ZmpA, BCAS0409, was upregulated 6-fold (Table 4) during growth in sputum, corroborating the data from animal studies that this is a core B. cenocepacia virulence factor. A second, as yet uncharacterised protease, BCAL0849 was also upregulated 3-fold (Table 4) suggesting it may also play a role during growth in sputum. However, no alteration in expression of ZmpB (BCAM2307), another well characterised Bcc protease [42], was detected.

\section{Gene clusters}

In addition to functional classification, we identified several clusters of genes where CDSs in close vicinity to each other demonstrated an altered expression (Table 4). These putative operons contained two or more genes with remarkably high values transcriptional fold change ( 2 to 90 fold) which further underlined a very likely co-regulation of their transcription. Two under expressed gene clusters represented well defined operons: the cable pilus operon (as described above; Table 4) and a cluster of urease structural protein genes (significantly downregulated were BCAL3104-6 and BCAL3109; Table 4). The remaining putatively co-regulated gene clusters comprised groups of genes that were either hypothetical or their functional classifications were rather general in nature. Out of these groups, a complex of nine consecutive hypothetical genes which all showed a 5-22 fold decrease in expression (BCAM0066-0074) was interesting. A similar cluster, also exhibiting coordinated expression of all genes but this time significant upregulation, comprised genes BCAM2749-2754 including the above mentioned hydroperoxide resistance gene ohr (Table 4). In the absence of functional data on these genes the physiological significance of these findings remain to be determined, however, they do illustrate the ability of transcriptomic analysis to reveal novel genes implicated in bacterial pathogenesis.
Several pairs of upregulated genes were identified which featured extreme changes in their expression. The highest values in the dataset were detected for the pair BCAL11061107 (cytochrome $\mathrm{b}$ and oxidoreductase; described above, Table 4). Other pairs of high expression were BCAL0269-0270 (oxidoreductase and ferric reductase; Table 4) and BCAM1676-1677 (nitrite/sulphite reductase and conserved hypothetical protein; Table 4).

A feature of the genomic content and evolution of Burkholderia bacteria is the presence of a large amount (approximately 10\%) of recently acquired DNA in the form of genomic islands $[2,12]$. However, very few of the differentially expressed CDSs were found to reside within $B$. cenocepacia J2315 genomic islands. This suggested that the factors necessary for pathoadaptation to cystic fibrosis and early growth in sputum were more inherent $B$. cenocepacia traits and were not recently acquired via mobile genetic elements. Only one island on the largest chromosome (designated BcenGI5; M. Holden, unpublished data), contained significant number of differentially expressed genes and this comprised a mixture of both upand down-regulated genes. Three of the upregulated CDSs (BCAL1153, 1156, 1157) comprise part of a putative hydroxybenzoate catabolism cluster, and includes a salicylaldehyde dehydrogenase (BCAL1153), which catalyses the conversion of salicylaldehyde to salicylate. Although it appears that the salicylaldehyde dehydrogenase is part of a horizontally acquired xenobiotic degradation pathway, this enzyme may also have an additional role in the iron metabolism of J2315 as discussed above. Seven genes within the island were downregulated (BCAL1130, 11611162, 1165-1166 and 1168-1169; Table 4) and were of no known function. Transcriptomic analysis also demonstrated that apart from downregulation of the quorumsensing regulator, cciIR (Table 4), no other gene on the Cenocepacia Pathogenicity Island (cci) [43] was altered in expression, suggesting that this island implicated in chronic lung infection is not extensively involved in rapid growth in CF sputum.

\section{Discussion}

Our study is the first full transcriptomic examination of a CF pathogen from the B. cepacia complex. We have extensively validated a custom microarray designed to the $B$. cenocepacia $\mathrm{J} 2315$ genome, demonstrating that it produces reproducible and quantitative results, as well as testing and confirming the growth models of iron-restriction and oxidative-stress formulated from the genomic expression profiles. Understanding how infecting bacteria colonize, grow and survive within sputum is fundamental to respiratory pathogenesis in $\mathrm{CF}$, and by examining six individuals in this study we also considerably expanded on previous work examining the transcriptomic response of the major CF pathogen, $P$. aeruginosa (a study where spu- 
tum from two CF patients was examined [13]). Many of the gene pathways activated by $B$. cenocepacia in response to growth in sputum correlated to known virulence mechanisms [2]; eg. antibiotic efflux and degradation, iron metabolism, resistance to host defenses and motility), however, what was particularly gratifying about the microarray data was its ability to identify novel genes involved in these functions and to highlight unexpected trends in B. cenocepacia gene expression after growth in sputum. As a method to examine virulence in an opportunistic pathogen with a large genome such as B. cenocepacia, our choice to use a microarray-based experimental strategy was fully validated.

The inability to clear Bcc bacteria from the CF lung with antibiotics frequently leads to chronic respiratory infection and the emergence of pan-resistant strains that require combination therapy to suppress [44]. Growth of B. cenocepacia in sputum revealed that 8 efflux pumps systems (3 that were members of the RND family) were altered in expression ( 4 up- and 4 down-regulated; Table 4). Thirteen putative multidrug efflux pumps of RND family have been characterised in B. cenocepacia J2315 genome; four of them have been shown to be transcriptionally active during the growth in Luria-Bertani medium, although their mode of expression (constitutive or regulated) was not elucidated [19]. Our transcriptomic data indicated that three of these RND pumps are under transcriptional regulation (BCAL1675, BCAL1813 and BCAM1947; Table 4) and not constitutively expressed in B. cenocepacia. These three RND systems and the five additional efflux transport systems highlighted by the microarray analysis are worthy of further study in relation to their role in growth and antibiotic resistance. Looking for inhibitors of these systems may improve the efficacy of current antibiotics as well as weaken the ability for B. cenocepacia to grow in sputum.

The B. cenocepacia ceo efflux system [20] was not activated in any of the sputum samples, an observation that correlated to the lack chloramphenicol, trimethoprim or ciprofloxacin therapy. The ceo pump is also known to actively efflux salicylate [20], whose biosynthetic pathway was upregulated in sputum along with several other ironacquisition systems. Nair et al. [20] hypothesized that there was a redundancy in salicylate transport systems since Bcc strains lacking a complete set of ceo genes were detected in their study, an observation that appears to be supported by the lack of $c e o$ expression yet siderophore overexpression seen in the microarray data. Candidate salicylate transporters may constitute the other sputum-activated RND efflux pumps (BCAL1675 and BCAM1947; Table 4).
It is also possible that the observed increase in RND pump expression (see above) may have also been induced by low iron concentrations rather than by presence of antibiotics per se. A link between iron, siderophore secretion and RND pump activity has been described in $P$. aeruginos $a$ where mutants lacking mexA or mexB RND efflux pump encoding genes were not able to grow on iron-deficient medium [45]. Factors involved in iron acquisition such as siderophores and their uptake mechanism are known to be important for B. cenocepacia virulence [21]. However, the microarray analysis also revealed potentially important roles for a ferric reductase in iron uptake and the frataxin-like cyaY gene in iron storage and the formation of Fe-S clusters. A link between CyaY and Fe-S protein biosynthesis has been recently proposed for prokaryotes [24]. Based on such evidence, we suggest that Fe-S cluster may play a primary role in iron storage during growth of B. cenocepacia in sputum.

Recently, Kohanski et al. [46] proposed a cascade of biochemical events which take place in bacterial cells when exposed to bactericidal antibiotics. The pathway, which is characterized by production of hydroxyl radicals via Fenton chemistry, may represent an ultimate killing mechanism of bactericidal antibiotics. In the Kohanski model, the formation of ROS occurs via oxidation of ferrous ions whose key intracellular source is thought to be iron-sulphur clusters [46]. Our study revealed significant changes in activity of several genes which may be pieces of the same puzzle in B. cenocepacia and represent the bacterial protective response against hydroxyl radicals: cyaY (a frataxin-like gene; BCAL0273), ohr (hydroperoxide resistance gene; BCAM2753) and iron acquisition genes (siderophores, salicylate biosynthesis and membrane ferric reductase). Since CF patients are on constant antimicrobial therapy, the large amounts of residual antibiotics in sputum may stimulate oxidation of free ferrous ions in the Fenton reaction, hence triggering an imbalance in intracellular iron distribution which results in the activation of the iron cycle genes we have observed in B. cenocepacia.

In addition to identifying potentially new $B$. cenocepacia virulence mechanisms, the transcriptomic analysis also revealed interesting trends in the expression of known virulence factors. For example, the upregulation of flagellar genes observed in B. cenocepacia contrasted markedly with the results of $P$. aeruginosa transcriptomic analysis, where the expression of flagella was repressed during the incubation in CF sputum [13]. While adaptation to a non-motile phenotype is a well-characterised trait of $P$. aeruginosa during chronic CF infection [47], this phenomenon has not been observed in Bcc bacteria. The upregulation of B. cenocepacia flagellar apparatus genes suggests that motility may allow this CF pathogen to maintain a more invasive 
phenotype during infection. Maintaining motility may also correlate to the fact that B. cenocepacia and other BCC bacteria retain their ability to cause a septic, invasive, "cepacia syndrome" at any point during chronic $\mathrm{CF}$ infection $[5,6]$.

Another example of an unexpected expression finding was the lack of activation of the structural components of cable pilus operon of B. cenocepacia J2315. Studies on a B. cenocepacia cable pilus knockout mutant showed that it was not altered in its capacity to bind lung epithelial cells [48], which taken together with our transcriptomic data, this suggests that the complete cable pilus may not be as important colonization surface structure as initially presumed [37]. However, we did find that the pilus-associated adhesin gene, adhA [38], was activated in sputum suggesting it is important for growth. In absence of cable pilus expression this finding also indicates that the AdhA adhesin may be incorporated onto other $B$. cenocepacia surface components.

Quorum sensing, the bacterial cell-to-cell communication system, controls many virulence genes functions in B. cenocepacia $[2,49,50]$. We did not detect expression changes in three of the characterized B. cenocepacia quorum sensing genes (i.e. $\mathrm{N}$-acylhomoserine lactone synthases cepI and $c c i I$, and a response regulator $c e p R[43,49])$. This may have due to the fact that $B$. cenocepacia was only allowed to grow to mid-log phase prior to microarray analysis, and quorum sensing activity only normally appears at later stages of growth. Limited signs of quorum sensing activity were apparent from the overexpression of polygalacturonase gene (BCAS0196), the zmpA metalloprotease and motility-associated flagellar genes, which are all under its control $[2,49,50]$. The only quorum sensing gene exhibiting altered expression (a 2.5-fold under-expression) was cciR (BCAM0240; Table 4) which encodes a quorum sensing transcriptional regulator known to be an autorepressor [49].

\section{Conclusion}

Studying opportunistic bacterial pathogens with large genomes, poor genetic tractability and limited models of infection is not straightforward. Our transcriptomic analysis of B. cenocepacia growth in a sputum-based model has provided a detailed snapshot of components of the J2315 genome that may promote colonisation and early growth in the CF lung. Transcriptomic analysis corroborated previous studies that had shown crucial roles for iron uptake and proteases in B. cenocepacia virulence. It also demonstrated that upregulation of efflux proteins and genes involved in antimicrobial stress are important. However, from the multiple genetic pathways encoding the latter phenotypic traits, microarray analysis demonstrated that previously uncharacterised $B$. cenocepacia genes such as a transmembrane ferric reductase (BCAL0270), protease (BCAL0849), organic hydroperoxide (BCAM2753), oxidoreductase (BCAL1107) and nitrite/sulfite reductase (BCAM1676), are significantly upregulated in sputum. In contrast to the pathogenesis of $P$. aeruginosa in CF lung infection, the expression of genes for motility and flagellar biosynthesis were upregulated, allowing $B$. cenocepacia to maintain a potentially invasive phenotype characteristic of cepacia syndrome. Virulence factors such as the structural cable pilus and genes on the cci were not upregulated during sputum growth suggesting they do not play an important role at the initial stage of infection we modelled. Overall, our successful transcriptomic analysis has revealed several new virulence $B$. cenocepacia virulence mechanisms worthy of further study and provided a reference set of gene expression data for growth of this pathogen in CF sputum.

\section{Competing interests}

The authors declare that they have no competing interests.

\section{Authors' contributions}

PD performed the microarray analysis, all experimental procedures associated with the transcriptomic study, and wrote the first draft of the manuscript. MTGH provided detailed correlation of the microarray data to the genome of $B$. cenocepacia. ZG provided assistance with the design of the microarray experiments and controls required to validate the performance of the arrays. AMJ and IK provided the clinical input concerning the cystic fibrosis individuals examined. RTG designed the $B$. cenocepacia custom microarray. EM conceived and planned the original study. PD, MTGH and EM wrote the paper and all authors have read the final manuscript.

\section{Additional material}

\section{Additional file 1}

Complete list of B. cenocepacia genes significantly upregulated after growth in CF sputum. B. cenocepacia genes that were significantly upregulated after growth in CF sputum are listed in a Microsoft Excel spreadsheet. The fields listed within the spreadsheet are: (i) the systematic gene identification number, (ii) the fold change in expression observed, (iii) its statistical significance in terms of a p value, (iv) the annotation and putative function of the genes and $(v)$ the type of feature (CDS $=$ coding sequence; $t R N A ; R N A$; or intergenic region).

Click here for file

[http://www.biomedcentral.com/content/supplementary/14712334-8-121-S1.xls] 


\section{Additional file 2}

Complete list of $\mathrm{B}$. cenocepacia genes significantly downregulated after growth in CF sputum. B. cenocepacia genes that were significantly downregulated after growth in CF sputum are listed in a Microsoft Excel spreadsheet. The fields listed within the spreadsheet are: (i) the systematic gene identification number, (ii) the fold change in expression observed, (iii) its statistical significance in terms of a p value, (iv) the annotation and putative function of the genes and $(v)$ the type of feature (CDS = coding sequence; $t R N A ; R N A$; or intergenic region).

Click here for file

[http://www.biomedcentral.com/content/supplementary/14712334-8-121-S2.xls]

\section{Acknowledgements}

We thank Angela Marchbank and Michael O'Reilly for excellent technical assistance.

This work was funded by a grant from the UK Wellcome Trust (E.M. grant number 075586) and the B. cenocepacia microarray development was funded by Cystic Fibrosis Foundation Therapeutics Inc. (grant MAHENT06V0). P.D. also acknowledges support from grant MSM 0021620812 , Ministry of Health, Czech Republic.

\section{References}

I. Govan JR, Brown AR, Jones AM: Evolving epidemiology of Pseudomonas aeruginosa and the Burkholderia cepacia complex in cystic fibrosis lung infection. Future Microbiol 2007, 2:153-164.

2. Mahenthiralingam E, Urban TA, Goldberg JB: The multifarious, multireplicon Burkholderia cepacia complex. Nat Rev Microbiol 2005, 3(2): | 144-156.

3. Drevinek P, Vosahlikova S, Cinek $O$, Vavrova V, Bartosova J, Pohunek $\mathrm{P}$, Mahenthiralingam E: Widespread clone of Burkholderia cenocepacia in cystic fibrosis patients in the Czech Republic. J Med Microbiol 2005, 54(Pt 7):655-659.

4. LiPuma JJ, Spilker T, Gill LH, Campbell PW 3rd, Liu L, Mahenthiralingam E: Disproportionate distribution of Burkholderia cepacia complex species and transmissibility markers in cystic fibrosis. Am J Resp Crit Care Med 200I, I64(I):92-96.

5. Jones AM, Dodd ME, Govan JR, Barcus V, Doherty CJ, Morris J, Webb AK: Burkholderia cenocepacia and Burkholderia multivorans: influence on survival in cystic fibrosis. Thorax 2004, 59(II):948-95I.

6. Mahenthiralingam E, Vandamme P, Campbell ME, Henry DA, Gravelle AM, Wong LT, Davidson AG, Wilcox PG, Nakielna B, Speert DP: Infection with Burkholderia cepacia complex genomovars in patients with cystic fibrosis: virulent transmissible strains of genomovar III can replace Burkholderia multivorans. Clin Infect Dis 200I, 33(9): I469-I475.

7. Vandamme P, Holmes B, Coenye T, Goris J, Mahenthiralingam E, LiPuma JJ, Govan JR: Burkholderia cenocepacia sp. nov. - a new twist to an old story. Res Microbiol 2003, I 54(2):91-96.

8. Govan JR, Brown PH, Maddison J, Doherty CJ, Nelson JW, Dodd M, Greening AP, Webb AK: Evidence for transmission of Pseudomonas cepacia by social contact in cystic fibrosis. Lancet 1993, 342(8862): 15-19.

9. Coenye T, Drevinek P, Mahenthiralingam E, Shah SA, Gill RT, Vandamme $P$, Ussery DW: Identification of putative noncoding RNA genes in the Burkholderia cenocepacia J2315 genome. FEMS Microbiol Lett 2007, 276(I):83-92.

10. Leiske DL, Karimpour-Fard A, Hume PS, Fairbanks BD, Gill RT: A comparison of alternative 60-mer probe designs in an in-situ synthesized oligonucleotide microarray. BMC Genomics 2006, 7:72.

II. Mahenthiralingam E, Drevinek P: Comparative genomics of Burkholderia species. In Burkholderia: Molecular Biology and Genomics Edited by: Coenye T, Vandamme P. Norwich: Horizon Scientific Press; 2007:53-79.
12. Holden MT, Titball RW, Peacock SJ, Cerdeno-Tarraga AM, Atkins T, Crossman LC, Pitt T, Churcher C, Mungall K, Bentley SD, et al: Genomic plasticity of the causative agent of melioidosis, Burkholderia pseudomallei. Proc Natl Acad Sci USA 2004, IOI(39): I 4240-I 4245.

13. Wolfgang MC, Jyot J, Goodman AL, Ramphal R, Lory S: Pseudomonas aeruginosa regulates flagellin expression as part of a global response to airway fluid from cystic fibrosis patients. Proc Natl Acad Sci USA 2004, I 0 I ( I 7):6664-6668.

14. Palmer KL, Mashburn LM, Singh PK, Whiteley M: Cystic fibrosis sputum supports growth and cues key aspects of Pseudomonas aeruginosa physiology. I Bacteriol 2005, I 87(15):5267-5277.

15. O'Sullivan LA, Weightman AJ, Jones TH, Marchbank AM, Tiedje JM, Mahenthiralingam E: Identifying the genetic basis of ecologically and biotechnologically useful functions of the bacterium Burkholderia vietnamiensis. Env Microbiol 2007, 9(4): I017-1034.

16. Baldwin A, Mahenthiralingam E, Thickett KM, Honeybourne D, Maiden MC, Govan JR, Speert DP, Lipuma JJ, Vandamme P, Dowson CG: Multilocus sequence typing scheme that provides both species and strain differentiation for the Burkholderia cepacia complex. J Clin Microbiol 2005, 43(9):4665-4673.

17. Pfaffl MW: A new mathematical model for relative quantification in real-time RT-PCR. Nucleic Acids Res 200I, 29(9):e45.

18. Eaves DJ, Ricci V, Piddock LJ: Expression of a crB, acrF, acrD, marA, and soxS in Salmonella enterica serovar Typhimurium: role in multiple antibiotic resistance. Antimicrob Agents Chemother 2004, 48(4): I I 45-I I 50.

19. Guglierame P, Pasca MR, De Rossi E, Buroni S, Arrigo P, Manina G, Riccardi G: Efflux pump genes of the resistance-nodulationdivision family in Burkholderia cenocepacia genome. $B M C$ Microbiol 2006, 6:66.

20. Nair BM, Cheung KJ Jr, Griffith A, Burns JL: Salicylate induces an antibiotic efflux pump in Burkholderia cepacia complex genomovar III (B. cenocepacia). J Clin Invest 2004, I I3(3):464-473.

21. Thomas MS: Iron acquisition mechanisms of the Burkholderia cepacia complex. Biometals 2007, 20(3-4):43।-452.

22. Sokol PA, Darling P, Lewenza S, Corbett CR, Kooi CD: Identification of a siderophore receptor required for ferric ornibactin uptake in Burkholderia cepacia. Infect Immun 2000, 68( I 2):6554-6560.

23. Duan K, Lafontaine ER, Majumdar S, Sokol PA: RegA, iron, and growth phase regulate expression of the Pseudomonas aeruginosa tol-oprL gene cluster. J Bacteriol 2000, I82(8):2077-2087.

24. Layer G, Ollagnier-de Choudens S, Sanakis Y, Fontecave M: Iron-sulfur cluster biosynthesis: characterization of Escherichia coli CyaY as an iron donor for the assembly of [2Fe-2S] clusters in the scaffold IscU. J Biol Chem 2006, 28I (24):16256-I6263.

25. Zeng AP, Kim EJ: Iron availability, oxygen limitation, Pseudomonas aeruginosa and cystic fibrosis. Microbiology 2004, 150:516-518.

26. Stites SW, Plautz MW, Bailey K, O'Brien-Ladner AR, Wesselius LI: Increased concentrations of iron and isoferritins in the lower respiratory tract of patients with stable cystic fibrosis. $\mathrm{Am} J$ Resp Crit Care Med 1999, 160(3):796-80I.

27. Mongkolsuk S, Praituan W, Loprasert S, Fuangthong M, Chamnongpol $S$ : Identification and characterization of a new organic hydroperoxide resistance (ohr) gene with a novel pattern of oxidative stress regulation from Xanthomonas campestris pv. phaseoli. J Bacteriol 1998, I 80( I 0):2636-2643.

28. Lesniak J, Barton WA, Nikolov DB: Structural and functional characterization of the Pseudomonas hydroperoxide resistance protein Ohr. EMBO / 2002, 2 I (24):6649-6659.

29. Conter A, Gangneux C, Suzanne M, Gutierrez C: Survival of Escherichia coli during long-term starvation: effects of aeration, $\mathrm{NaCl}$, and the rpoS and osmC gene products. Res Microbiol 200I, I52(I):17-26.

30. Lefebre $M$, Valvano $M$ : In vitro resistance of Burkholderia cepacia complex isolates to reactive oxygen species in relation to catalase and superoxide dismutase production. Microbiology 200I, I 47(Pt I):97-109.

31. Fang FC: Antimicrobial reactive oxygen and nitrogen species: concepts and controversies. Nat Rev Microbiol 2004, 2(10):820-832. 
32. Poock SR, Leach ER, Moir JW, Cole JA, Richardson DJ: Respiratory detoxification of nitric oxide by the cytochrome c nitrite reductase of Escherichia coli. J Biol Chem 2002, 277(26):23664-23669.

33. Speert DP: Advances in Burkholderia cepacia complex. Paediatric $\operatorname{Resp} \operatorname{Rev} 2002$, 3(3):230-235.

34. Tomich M, Herfst CA, Golden JW, Mohr CD: Role of flagella in host cell invasion by Burkholderia cepacia. Infect Immun 2002, 70(4): $1799-1806$.

35. Schoenhals GJ, Kihara M, Macnab RM: Translation of the flagellar gene fliO of Salmonella typhimurium from putative tandem starts. J Bacteriol I998, I 80( I I):2936-2942.

36. Kachlany SC, Planet PJ, Desalle R, Fine DH, Figurski DH, Kaplan JB: flp- $I$, the first representative of a new pilin gene subfamily, is required for non-specific adherence of Actinobacillus actinomycetemcomitans. Mol Microbiol 200I, 40(3):542-554.

37. Sajjan US, Xie H, Lefebre MD, Valvano MA, Forstner JF: Identification and molecular analysis of cable pilus biosynthesis genes in Burkholderia cepacia. Microbiology 2003, 149(Pt 4):96I-97I.

38. Sajjan US, Forstner JF: Role of a 22-kilodalton pilin protein in binding of Pseudomonas cepacia to buccal epithelial cells. Infect Immun 1993, 6I(8):3157-3163.

39. Peabody CR, Chung YJ, Yen MR, Vidal-Ingigliardi D, Pugsley AP, Saier $\mathrm{MH}$ Jr: Type II protein secretion and its relationship to bacterial type IV pili and archaeal flagella. Microbiology 2003, I49(Pt II):305I-3072.

40. Aizawa SI: Bacterial flagella and type III secretion systems. FEMS Microbiol Lett 200I, 202(2): I57-164.

4I. Corbett CR, Burtnick MN, Kooi C, Woods DE, Sokol PA: An extracellular zinc metalloprotease gene of Burkholderia cepacia. Microbiology 2003, I49(Pt 8):2263-227I.

42. Kooi C, Subsin B, Chen R, Pohorelic B, Sokol PA: Burkholderia cenocepacia $\mathrm{ZmpB}$ is a broad-specificity zinc metalloprotease involved in virulence. Infect Immun 2006, 74(7):4083-4093.

43. Baldwin A, Sokol PA, Parkhill J, Mahenthiralingam E: The Burkholderia cepacia epidemic strain marker is part of a novel genomic island encoding both virulence and metabolism-associated genes in Burkholderia cenocepacia. Infect Immun 2004, 72(3): 1537-1547.

44. Aaron SD, Ferris W, Henry DA, Speert DP, Macdonald NE: Multiple combination bactericidal antibiotic testing for patients with cystic fibrosis infected with Burkholderia cepacia. Am J Resp Crit Care Med 2000, I6I(4 Pt I):1206-12I2.

45. Poole $K$, Heinrichs DE, Neshat $S$ : Cloning and sequence analysis of an EnvCD homologue in Pseudomonas aeruginosa: regulation by iron and possible involvement in the secretion of the siderophore pyoverdine. Mol Microbiol 1993, I0(3):529-544.

46. Kohanski MA, Dwyer DJ, Hayete B, Lawrence CA, Collins J]: A common mechanism of cellular death induced by bactericidal antibiotics. Cell 2007, I 30(5):797-8I0.

47. Mahenthiralingam E, Campbell ME, Speert DP: Nonmotility and phagocytic resistance of Pseudomonas aeruginosa isolates from chronically colonized patients with cystic fibrosis. Infect Immun 1994, 62(2):596-605.

48. Tomich M, Mohr CD: Adherence and autoaggregation phenotypes of a Burkholderia cenocepacia cable pilus mutant. FEMS Microbiol Lett 2003, 228(2):287-297.

49. Malott RJ, Baldwin A, Mahenthiralingam E, Sokol PA: Characterization of the ccilR quorum-sensing system in Burkholderia cenocepacia. Infect Immun 2005, 73(8):4982-4992.

50. Sokol PA, Sajjan U, Visser MB, Gingues S, Forstner J, Kooi C: The CepIR quorum-sensing system contributes to the virulence of Burkholderia cenocepacia respiratory infections. Microbiology 2003, I49(Pt I 2):3649-3658.

\section{Pre-publication history}

The pre-publication history for this paper can be accessed here:

http://www.biomedcentral.com/1471-2334/8/121/pre pub
Publish with Biomed Central and every scientist can read your work free of charge

"BioMed Central will be the most significant development for disseminating the results of biomedical research in our lifetime. "

Sir Paul Nurse, Cancer Research UK

Your research papers will be:

- available free of charge to the entire biomedical community

- peer reviewed and published immediately upon acceptance

- cited in PubMed and archived on PubMed Central

- yours - you keep the copyright

Submit your manuscript here:

http://www.biomedcentral.com/info/publishing_adv.asp
BiolMedcentral 